\title{
Large enhancements in low latitude total electron content during 15 May 2005 geomagnetic storm in Indian zone
}

\author{
N. Dashora ${ }^{1}$, S. Sharma ${ }^{2}$, R. S. Dabas ${ }^{3}$, S. Alex ${ }^{4}$, and R. Pandey ${ }^{2}$ \\ ${ }^{1}$ National Atmospheric Research Laboratory, Gadanki, Department of Space, Government of India - 517 112, India \\ ${ }^{2}$ Department of Physics, M. L. S. University, Udaipur-313 001, India \\ ${ }^{3}$ National Physical Laboratory, New Delhi, 110 012, India \\ ${ }^{4}$ Indian Institute of Geomagnetism, Navi Mumbai, 410 206, India
}

Received: 25 August 2008 - Revised: 26 November 2008 - Accepted: 26 November 2008 - Published: 4 May 2009

\begin{abstract}
Results pertaining to the response of the equatorial and low latitude ionosphere to a major geomagnetic storm that occurred on 15 May 2005 are presented. These results are also the first from the Indian zone in terms of (i) GPS derived total electron content (TEC) variations following the storm (ii) Local low latitude electrodynamics response to penetration of high latitude convection electric field (iii) effect of storm induced traveling atmospheric disturbances (TAD's) on GPS-TEC in equatorial ionization anomaly (EIA) zone.

Data set comprising of ionospheric TEC obtained from GPS measurements, ionograms from an EIA zone station, New Delhi (Geog. Lat. 28.42 ${ }^{\circ} \mathrm{N}$, Geog. Long. $77.21^{\circ} \mathrm{E}$ ), ground based magnetometers in equatorial and low latitude stations and solar wind data obtained from Advanced Composition Explorer (ACE) has been used in the present study. GPS receivers located at Udaipur (Geog. Lat. $24.73^{\circ} \mathrm{N}$, Geog. Long. $73.73^{\circ}$ E) and Hyderabad (Geog. Lat. $17.33^{\circ} \mathrm{N}$, Geog. Long. $78.47^{\circ} \mathrm{E}$ ) have been used for wider spatial coverage in the Indian zone. Storm induced features in vertical TEC (VTEC) have been obtained comparing them with the mean VTEC of quiet days. Variations in solar wind parameters, as obtained from ACE and in the SYM-H index, indicate that the storm commenced on 15 May 2005 at 02:39 UT. The main phase of the storm commenced at 06:00 UT on 15 May with a sudden southward turning of the Z-component of interplanetary magnetic field (IMF- $B_{z}$ ) and subsequent decrease in SYM-H index. The dawn-to-dusk convection electric field of high latitude origin penetrated to low and equatorial latitudes simultaneously as corroborated by the mag-
\end{abstract}

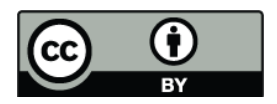

Correspondence to: N. Dashora (nirvikardashora@gmail.com) netometer data from the Indian zone. Subsequent northward turning of the IMF- $B_{z}$, and the penetration of the dusk-todawn electric field over the dip equator is also discernible. Response of the low latitude ionosphere to this storm may be characterized in terms of (i) enhanced background level of VTEC as compared to the mean VTEC, (ii) peaks in VTEC and $f o \mathrm{~F} 2$ within two hours of prompt penetration of electric field and (iii) wave-like modulations in VTEC and sudden enhancement in $h m \mathrm{~F} 2$ within $4-5 \mathrm{~h}$ in to the storm. These features have been explained in terms of the modified fountain effect, local low latitude electrodynamic response to penetration electric field and the TIDs, respectively. The study reveals a strong positive ionospheric storm in the Indian zone on 15 May 2005. Consequences of such major ionospheric storms on the systems that use satellite based navigation solutions in low latitude, are also discussed.

Keywords. Ionosphere (Equatorial ionosphere; Ionospheremagnetosphere interactions) - Magnetospheric physics (Solar wind-magnetosphere interactions)

\section{Introduction}

In recent years, the Global Positioning System (GPS) has emerged to be a very important and powerful tool in the investigation of the ionosphere. Continuous availability and redundancy of the GPS satellites in spatial and temporal domains, all over the globe, signify their importance in ionospheric studies. Owing to its continuous operation in all weather conditions and the signal reception with high time resolution, monitoring the ionosphere with GPS receivers is now a widely used procedure, both regionally and globally. Total electron content (TEC) between a dual frequency

Published by Copernicus Publications on behalf of the European Geosciences Union. 
receiver and a constellation of GPS satellites is calculated from L1 and L2 carrier signals and codes transmitted simultaneously by the GPS satellites. The TEC is the measure of electrons contained in a cylinder of unit cross section between a receiver and a satellite along the line of sight. The TEC thus obtained is an important parameter for the study of ionospheric variations and dynamics. However, sudden variations in TEC degrade the phase and amplitude of the received GPS signal and hence are an impediment to the transionospheric communication and navigation. In the low latitude zone, signal degradation may be more likely because of large variations in TEC near the crest of the equatorial ionization anomaly (EIA), owing to very large background TEC values.

During the geomagnetic storms, it has been observed that the TEC varies drastically at almost all latitudes on global and regional scales (Ho et al., 1996; Jakowaski et al., 1999; Maruyama et al., 2004; Zhao et al., 2005; Foster and Rideout, 2005). Large variations in TEC during the geomagnetic storms introduce additional range errors in the EIA zone latitudes (Liu et al, 1999; Basu et al., 2001, 2005; Lin et al., 2004; Dashora and Pandey, 2007a) for the reasons as noted above and therefore, the navigational errors become more grievous in the EIA zone during geomagnetic storms. Ionospheric response, in terms of TEC, to a geomagnetic storm is different depending on the geographic location of the receiver, and the strength and local time of occurrence of the storm (Tsurutani et al., 2004; Mannucci et al., 2005). Until a complete understanding of the processes that lead to an ionospheric storm develops, variations in TEC during each storm require to be investigated in real time to mitigate the errors in GPS navigation.

Effects of storm time electrodynamics, neutral winds and subsequent compositional changes, show both increase and decrease in the ionospheric F-region density (Kumar et al., 2005), characterized by positive and negative ionospheric storms, respectively (Buonsanto, 1999). The electrodynamic effects of the geomagnetic storm manifest on varied time scales and include the prompt penetration of the convection electric field and the disturbance dynamo electric field.

The sudden southward turning of the z-component of the interplanetary magnetic field (i.e. IMF- $B_{z}$ ), from a steady northward configuration, produces a dawn to dusk convection electric field at high latitudes (Nishida, 1968, Somayajulu et al., 1987; Sastri et al., 1992a, b; Kikuchi et al., 1996, 2008). This creates the so-called under-shielding condition and the region-1 electric field penetrates instantaneously to the equatorial and low latitudes (Kikuchi and Araki, 1979; Kikuchi, 1996). It operates on time scales of an hour or so and is called the prompt penetration electric field (Fejer et al., 2007, and references therein). However, after a steady southward configuration, the IMF- $B_{z}$ turns northward again and the over-shielding condition occurs. In this case, the existing region-2 electric field penetrates the equatorial and low latitudes (Kelley et al., 1979; Sastri et al., 1992a, b; Kikuchi et al., 2008). In this paper, we discuss the effects of the prompt penetration electric fields, originating due to under and over shielding conditions, on equatorial and low latitude ionosphere.

The enhanced energy deposition during the main phase of the geomagnetic storms and subsequent Joule heating in the high latitudes modifies the global thermospheric wind circulation resulting in disturbance dynamo electric field (Blanch and Richmond, 1980). The disturbance dynamo fields manifest on time scales of a few hours to days in the low latitude ionosphere.

In addition to these electrodynamic processes, the impulsive heat inputs in the auroral zone may generate a spectrum of atmospheric gravity waves (AGWs) that disperse as they propagate away from the source. These waves are called traveling atmospheric disturbances (TADs) (Hines, 1960, 1974; Richmond, 1978; Jing and Hunsucker, 1993; Balthazor and Moffet, 1997). The TADs are manifested in the ionosphere as Traveling Ionospheric Disturbances (TIDs) (Millward et al., 1993; Hocke and Schlegel, 1996; Kirchengast et al., 1996). Once the equator-ward propagating TADs arrive at middle latitudes, the associated meridional wind causes an uplift in the peak height of the F-region ( $h m \mathrm{~F} 2)$, which in turn leads to an initial decrease followed by a subsequent increase in the peak density of the F-region $(\mathrm{Nm} \mathrm{F} 2)$ (Bauske and Prolss, 1997). According to Prolss (1993) and Bauske and Prolss (1997), the TAD is an impulse-like perturbation formed by a superposition of gravity waves, which propagates with high velocity (e.g. $\sim 600 \mathrm{~m} / \mathrm{s}$ ) in meridional direction. It has been emphasized that AGWs affect the ionosphere primarily through their meridional winds, which drag the ionization along the inclined magnetic field lines (Kirchengast et al., 1996; Sastri et al., 2000). The height of the ionization layer is thus changed and an increase in layer height leads to a positive ionospheric storm if the height dependence of ionization production and loss is considered. The effect of storm induced TIDs on TEC has been studied in high and mid latitudes (Afraimovich et al., 2000; Tsugawa et al., 2004, 2006; Nicolls et al., 2004; Ding et al., 2007), but the same has not been reported from equatorial and low latitude zone so far. In this paper, we present the results of a positive ionospheric storm that followed a geomagnetic storm on 15 May 2005 in local daytime in the Indian zone. These are the first results concerning this storm from the region wherein, the observed ionospheric density enhancements have been attributed to (i) the prompt penetration electric field and (ii) to the TADs.

\section{Solar wind and geomagnetic conditions}

An eruption of a solar active region AR 10759 produced a fast halo coronal mass ejection (CME) and was associated with a long-duration M8 class X-ray flare with peak emission at 16:57 UT on 13 May 2005. The disturbance arrived at the earth on 15 May 2005. The interplanetary event, 


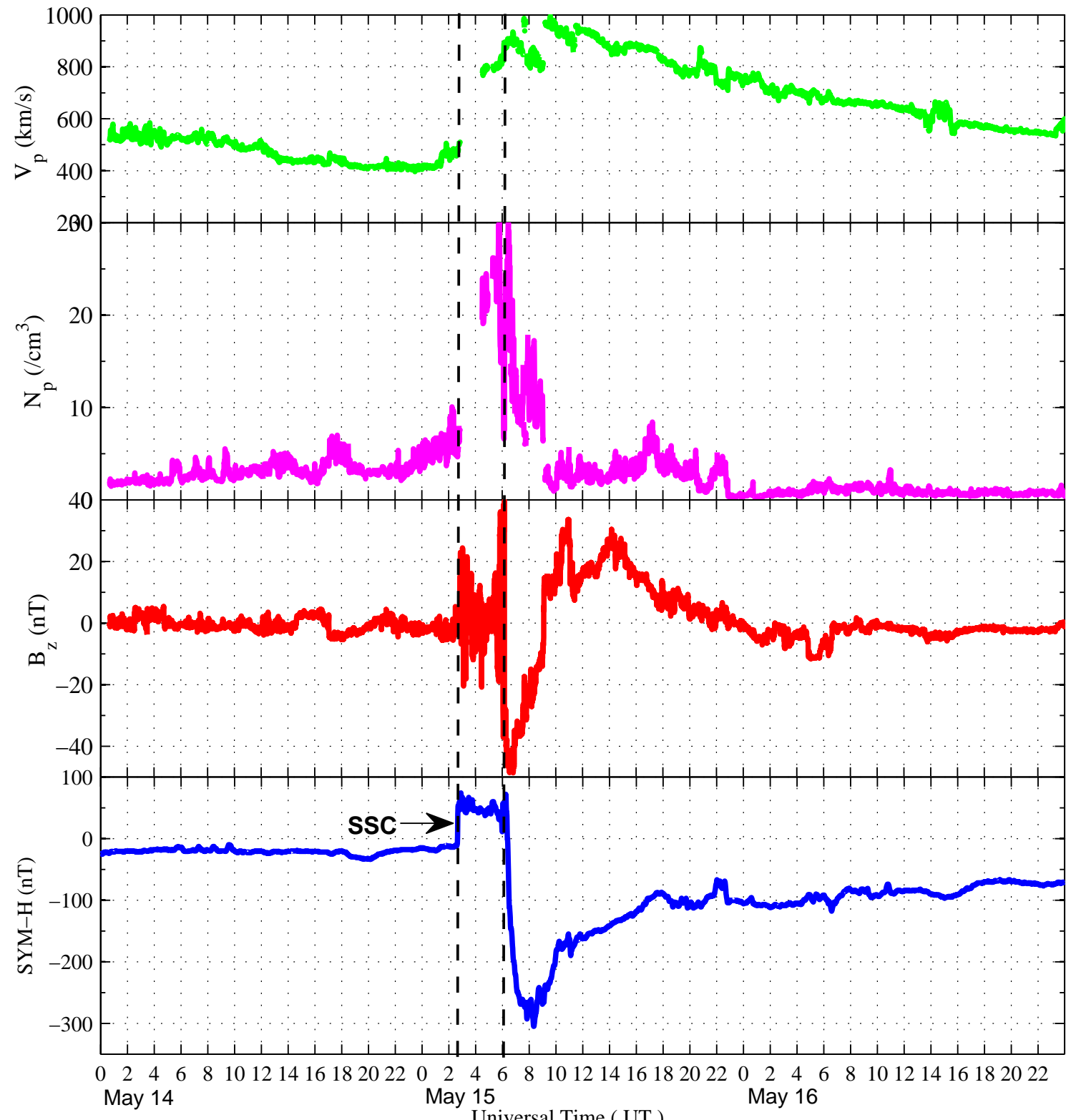

Fig. 1. The solar wind and geomagnetic parameters from 14-16 May 2005. Three panels from top are the solar wind (proton) speed (green), the proton density (magenta), the IMF- $B_{z}$ (red) as measured by ACE spacecarft and SYM-H index (blue) at bottom.

corresponding to the geomagnetic storm of 15 May 2005, is shown in Fig. 1, for the period 14 to 16 May 2005. The panels from the top are the interplanetary parameters - solar wind (proton) speed, the proton density and the IMF- $B_{z}$ with time resolution of 64, 64 and $16 \mathrm{~s}$, respectively. These parameters were measured from the Advanced Composition Explorer (ACE) satellite and were obtained as level 2 data from the web-site http://www.srl.caltech.edu/ACE/ASC/. The bottom panel of the figure shows variation of the symmetric geomagnetic disturbance index, SYM-H, which is the horizontal component of the geomagnetic disturbance field (Iyemori and Rao, 1996). The SYM-H index is essentially the same as hourly $D_{s t}$ index, except that its time resolution is $1 \mathrm{~min}$. The SYM-H index for the interval 14-16 May 2005 was obtained from the WDC-Kyoto web site.

In preparing Fig. 1 the solar wind parameters have been shifted in time, in accordance with the storm sudden commencement (SSC) as observed in SYM-H index. This has been done for better comparison of the parameters obtained from the satellite and ground based instruments. This also minimizes the errors in computation of time shifts that are encountered in computing the shock arrival time from ACE 
satellite to the magnetopause by using the solar wind speed information. Thus, the SSC occurred at 02:39 UT on 15 May 2005 as indicated by a vertical heavy dashed line. An arrow at the same time, in the bottom panel of Fig. 1, indicates the time of SSC as recognized in SYM-H index. The solar wind speed and proton density data for the period of 02:10 UT to 03:48 UT was not available and hence the interplanetary shock is not visible at the time of SSC. However, the shock is obvious in the data after 03:48 UT. The shock has been identified by an abrupt increase in the solar wind speed from about $400 \mathrm{~km} / \mathrm{s}$ to $1000 \mathrm{~km} / \mathrm{s}$, a density increase from about $4 \mathrm{~cm}^{-3}$ to $30 \mathrm{~cm}^{-3}$.

The sudden decrease of IMF- $B_{z}$ to $-45 \mathrm{nT}$ at 06:00 UT caused a sharp decrease in SYM-H index value and commenced the main phase of the geomagnetic storm. The lowest value of SYM-H index being $-305 \mathrm{nT}$ at around 08:20 UT on 15 May. Therefore, as per the categorization of the geomagnetic storms based on minimum $D_{s t}$ index values (Gonzalez et al., 1994), this storm falls under major geomagnetic storm. Rapidly decreasing IMF- $B_{z}$ causes the sudden increase in polar cap potential, resulting in the generation of sudden region- 1 currents. The region- 2 currents (the lower latitude current system in the auroral region due to Alfvén layer shielding charges generated by the ring current) cannot respond at the same rate. Thus the high latitude electric potential, which is normally shielded by the region- 2 currents, can reach much lower latitudes (Peymirat et al., 2000). The condition is called under-shielding, which results in prompt penetration of interplanetary electric fields to low latitudes and equator. The prompt penetration (hereafter stated as PP) electric fields are transmitted almost instantaneously to the low latitudes (Arakai and Kikuchi, 1979). But the efficiency and amplitude of the transmitted electric field depends on the conductivity distribution in equatorial and low latitude ionosphere (Gonzalez et al., 1983). Recent studies (Maruyama et al., 2005) have shown that such penetration of the electric field is more effective during daytime. For a sudden decrease (increase) of IMF- $B_{z}$ and subsequent occurrence of under-shielding (over-shielding) condition, the PP fields are directed eastward (westward) during the day and westward (eastward) during the night, producing perturbed upward (downward) and downward (upward) vertical ionospheric drifts, respectively in the low latitude and equatorial ionosphere. Hence, the PP electric fields of both kinds produce remarkable effects in the low latitude and equatorial ionosphere, depending upon the strength and rate of change of IMF- $B_{z}$, and their local time of occurrence (Fejer et al., 2007). The evidence that the high latitude convection electric field had penetrated to low latitudes at 06:00 UT on 15 May, can only be given through proxy measurements, because, direct measurements of the zonal winds and ionospheric electric fields of E-region are practically difficult (Kelley, 1989). The daytime ionospheric E-region electric fields have direct bearing on F-region zonal and vertical drifts. The Incoherent Scatter Radars (ISR) can precisely measure these drifts
(Woodman, 1970; Fejer, 1991; Kudeki et al., 1999) and the measured F-region drifts can significantly be used as a proxy to the electric fields. In the absence of F-region vertical drift measurements, the other proxy to the electric field may be the changes in the horizontal component of the magnetic field over the equator, due to changes in the primary eastwest electric field and its response observed in the horizontal currents. The use of such proxy largely depends on the conductivity distribution in the ionosphere, although, the same has been extensively used in equatorial latitudes. Observations from magnetometer data have been used to determine the effect of high latitude electric fields in equatorial and low latitudes during geomagnetically disturbed conditions (e.g. Nishida, 1968, and recently by Kikuchi et al., 1996, 2000, 2008, and references therein). Such observations have also been useful during quiet periods for correlating the strengths of EEJ current and EIA in low latitudes (e.g. Rastogi and Klobuchar, 1990). Chandra and Rastogi (1974), Balan and Iyer (1983), Sastri (1988), Rastogi and Klobucher (1990), Sastri et al. (2000) and Rastogi (2000) have studied earlier the relationship between variations in the $\mathrm{H}$ component of the geomagnetic field with the strength of the EEJ and with the equatorial vertical drift velocity. Recently, Anderson et al. $(2002,2004,2006)$ have tried to quantify such correlations. It is now well established that under the geomagnetic quiet conditions, the EEJ as well as the daytime F-region vertical plasma drift predominantly depends upon the E-region dynamo process (Heelis, 2004). Hence, the primary eastwest electric field over the equator and in low latitudes plays an important role in modifying the equatorial E- and F-region electrodynamics (Fejer and Scherliess, 2001). In case of an external (penetration) electric field simultaneously imposed over the equator and low latitudes, the effects produced by the same field in the two regions are of different magnitudes. The external electric field may cause large current over dip equator and may produce large magnetic fluctuations over there, but in low latitudes, the same externally imposed electric field may not produce large currents due to much smaller conductivities and, hence, very small magnetic fluctuation in $\mathrm{H}$ component would occur.

Another point that we wish to highlight is the relationship between the daytime low latitude primary eastward electric field and the equatorial F-region vertical $\boldsymbol{E} \times \boldsymbol{B}$ drift. Due to the high parallel conductivity in daytime, efficient mapping of the low latitude E-region zonal electric field to equatorial F-region is possible. Thus, the low latitude east-west electric field may be observed without much attenuation in the Fregion over the dip equator. Thus, the major contribution for the daytime equatorial F-region vertical $\boldsymbol{E} \times \boldsymbol{B}$ drift comes from the low latitude E-region dynamo. The daytime equatorial F-region $\boldsymbol{E} \times \boldsymbol{B}$ drift then produces a remarkable fountain effect over the equator, resulting in the EIA on both sides of the dip equator in \pm 20 degree in the low latitudes. During geomagnetic disturbed conditions, the high latitude electric field penetrates to equatorial and low latitudes. As noted 
above, the direction of the penetration electric field during daytime is eastward (westward) for under (over)-shielding. Hence, sudden transformations in the primary east-west electric field in low latitudes occur at the time of penetration of high latitude electric field. This disturbance electric field then maps to equatorial F-region, which in turn causes sudden modifications in the F-region vertical $\boldsymbol{E} \times \boldsymbol{B}$ drift over the equator as observed and reported by many authors using different techniques like ionosonde, radar and satellite measurements (Sastri, 1992a, b; Fejer and Scherliess, 1995; Fejer et al., 2007; Kelley et al., 1979; Abdu, 1997; Kil, 2007).

Anderson et al. $(2002,2006)$ and other authors have attempted to empirically relate the daytime equatorial F-region vertical $\boldsymbol{E} \times \boldsymbol{B}$ drift with the $\Delta H$ measurements, stating that the $\Delta H$ might serve as a proxy to the electric field. This electric field may be of E-region dynamo or the high latitude origin. The $\Delta H$ is a measure of EEJ strength and since, during daytime, the zonal electric field is a common physical quantity between them, seeking correlation may be logical but may not be physical. As noted above, for a small increment in the equatorial primary eastward electric field, the EEJ current strength may be large, resulting in large $\Delta H$ values. Whereas, the similar increment in the low latitude electric field may not be able to enhance the equatorial Fregion vertical drift up to the same order of magnitude. There is a proportionality factor of ionospheric conductivity between the EEJ current strength and the daytime equatorial eastward electric field. Therefore, a linear relationship (of kind $\Delta H=A . \boldsymbol{E} \times \boldsymbol{B}$ drift $+\mathrm{C}$, with two coefficients $A$ and $C$ ) exists between the $\Delta H$ and the daytime F-region equatorial vertical drift (see Anderson et al., 2002). First coefficient $A$, is the slope of the linear fit and the second coefficient $C$ is a constant factor. Both the coefficients would vary with regard to latitude, longitude, solar activity (i.e. solar flux) and season. To illustrate this variability, Anderson et al. (2006) and Anghel et al. (2007) have attempted to provide such empirical relationships for three different longitude sectors for different seasons and solar activity conditions by using several numerical techniques.

During the daytime prompt penetration of high latitude electric field in the low latitudes, sudden modifications in the total electric field in the low latitudes occur. This would suddenly increase/decrease the vertical component of the low latitude F-region $\boldsymbol{E} \times \boldsymbol{B}$ drift. As noted above, the local low latitude F-region vertical drift would also play a significant role in the modification of the low latitude electron density and the TEC. A significant aspect of daytime equatorial and low latitude electrodynamic processes is the associated time lag. From the time of start of the vertical drift over the equator to production of the EIA, there is a certain time lag and shows that the build up of EIA is a slow process. Some of the earlier studies have shown that EIA develops after a delay of about 3-4 h in response to the development of primary east-west electric field (Rastogi and Klobuchar, 1990). This delay may vary under different seasons and variable iono- spheric background conditions. Therefore, starting from the strength of EEJ on the storm day, we show the observations in the EIA zone in the following.

Observations of horizontal component of geomagnetic field $(\mathrm{H})$ from two stations in the Indian zone, Tirunelveli (Geog. Lat. $8.42^{\circ} \mathrm{N}$, Geog. Long. $77.48^{\circ} \mathrm{E}$, Geomag. Lat. $0.57^{\circ} \mathrm{S}$ ) and Alibagh (Geog. Lat. $18.63^{\circ} \mathrm{N}$, Geog. Long. $72.87^{\circ} \mathrm{E}$, Geomag. Lat. $10.03^{\circ} \mathrm{N}$ ) have been used to infer the direction of the PP electric field, and hence the vertical movements of F-region plasma over equator. Observations of $\mathrm{H}$ component of geomagnetic field, with 1-min resolution, obtained from ground-based magnetometers have been used for the purpose. The $\mathrm{H}$ component data from both the stations has been separately corrected for nighttime base level for the month of May 2005 to obtain $\Delta H_{\mathrm{TIR}}$ and $\Delta H_{\mathrm{ABG}}$. Figure 2 shows the difference $\left(\Delta H_{\mathrm{TIR}}-\Delta H_{\mathrm{ABG}}\right)$ for 15 May 2005. Three features, in the difference, $\left(\Delta H_{\mathrm{TIR}}-\Delta H_{\mathrm{ABG}}\right)$, measured on 15 May 2005 are evident. The first one is the sudden impulse with a maximum value of about $30 \mathrm{nT}$ at about 02:40 UT, corresponding to the storm sudden commencement (SSC). The second is concerned with the large impulse, with a peak value of about $220 \mathrm{nT}$, at about 06:10 UT. This involves penetration of high latitude convection electric field over the dip equator. The third one is concerned with features that are seen after the peak. The difference $\left(\Delta H_{\mathrm{TIR}}-\Delta H_{\mathrm{ABG}}\right)$ then sharply decreased to $-115 \mathrm{nT}$ at around 08:20 UT. It fluctuated between $-50 \mathrm{nT}$ and $-120 \mathrm{nT}$ up to 09:30 UT. The difference then sharply increased and became positive at about 11:05 UT. Large variations in the difference, $\left(\Delta H_{\mathrm{TIR}}-\Delta H_{\mathrm{ABG}}\right)$, as observed after 06:00 UT, represent the complexities associated with the storm-induced variations, first, in the east-west electric field over dip equator, then in EEJ current strength. The large increments exhibit enhanced eastward electric field over dip equator and enhanced EEJ current. The large decrements exhibit decreased eastward or enhanced westward electric field over dip equator and counter EEJ (CEEJ) current. Also, there is a significant correlation between the variations of IMF- $B_{z}$ (Fig. 1) and ( $\left.\Delta H_{\mathrm{TIR}}-\Delta H_{\mathrm{ABG}}\right)$.

\section{Observations}

\subsection{Total Electron Content (TEC)}

The GPS signal recorded by two dual frequency receivers, one located at Udaipur (Geog. Lat. $24.73^{\circ} \mathrm{N}$, Geog. Long. $73.73^{\circ} \mathrm{E}$ ) and the other at Hyderabad (Geog. Lat. $17.33^{\circ} \mathrm{N}$, Geog. Long. $78.47^{\circ} \mathrm{E}$ ) have been used in the study. GPS receivers provide the line of sight (slant) TEC for each receiversatellite pair. Inherent to these measurements are the GPS receiver and satellite bias errors. These errors have to be estimated and removed during the post processing of the data. But, these errors do not pose a serious threat to the studies covering shorter periods of about one week or so, as the 


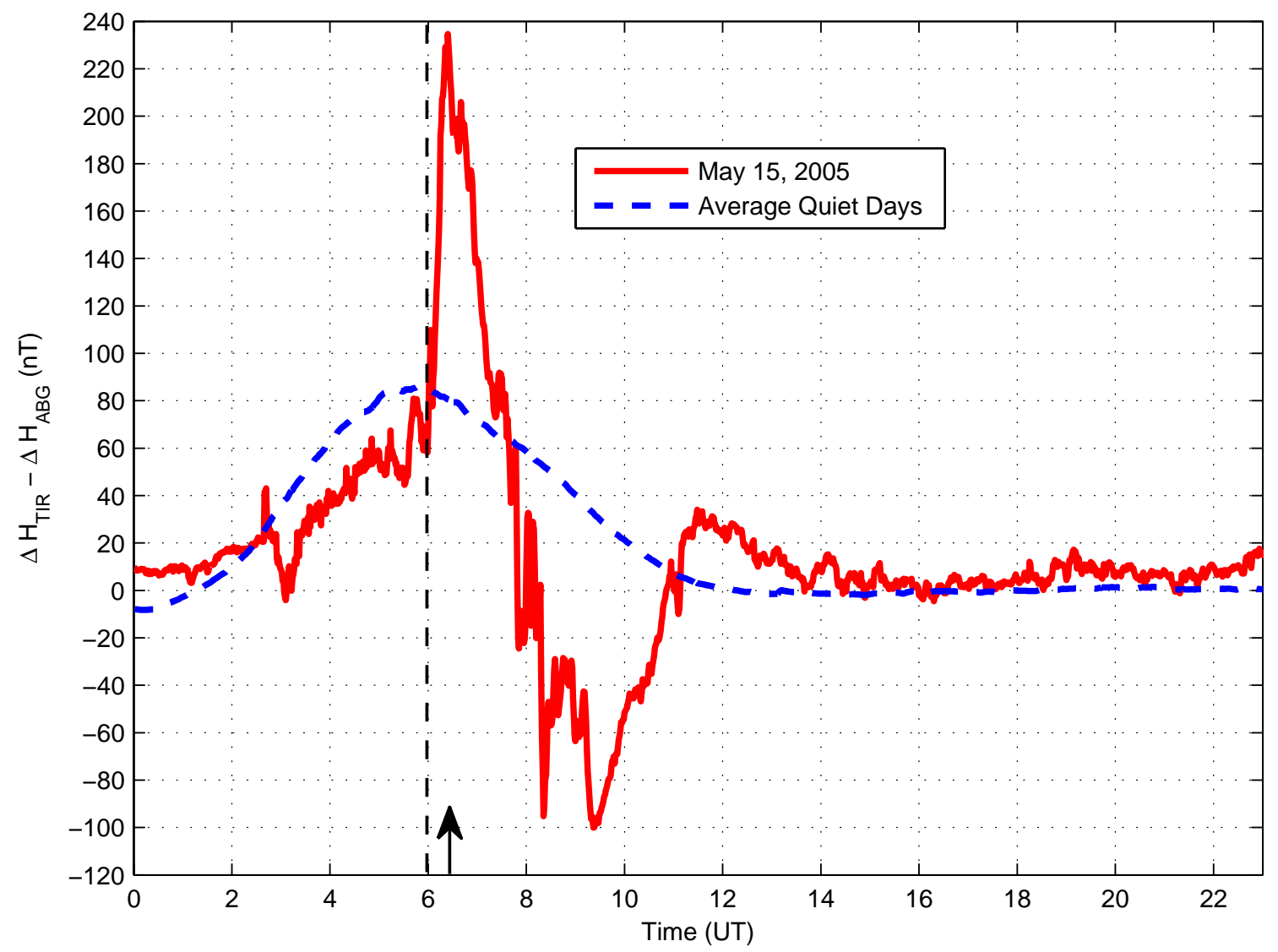

Fig. 2. The ( $\left.\Delta H_{\mathrm{TIR}}-\Delta H_{\mathrm{ABG}}\right)$, estimated using Tirunaveli (equatorial) and Alibagh (non-equatorial) magnetometer data with 1 min resolution. Variation on 15 May 2005 (red solid line) and for mean of quiet days (blue-broken line) are shown for comparison. The vertical dashed line at 06:00 UT represent the time of PP of electric field and the vertical arrow at about 06:30 UT shows the sudden reversal in the quantity.

errors are known to vary over periods of weeks to months. In the present case, as we are interested in comparing the storm time TEC values with the quiet time TEC values of nearby period of a few days, these errors have not been removed completely. The RINEX (Gurtner, 1994) observation files for Hyderabad station have been obtained from IGS (International GNSS Service) web-site. The time resolution of the RINEX data obtained from Hyderabad station is $30 \mathrm{~s}$ and that from Udaipur station is $60 \mathrm{~s}$. All the steps, beginning right from the GPS data pre-processing to estimating the VTEC as a product, have been accomplished with the software developed by Dashora and Pandey (2007b). The slant TEC has been calculated from RINEX data after the detection and correction for the cycle slips and outliers using the algorithm of Blewitt (1990). The slant TEC, thus obtained, has been converted into vertical TEC (VTEC) following the procedure of Ma and Maruyama (2003). For this, a thin ionospheric shell at an altitude of $350 \mathrm{~km}$ has been assumed. The latitudes and longitudes of ionospheric pierce points (IPPs) have been computed from the RINEX Navigation Message data by using standard coordinate transformation formulae and correc- tions in satellite orbits (Hoffmann-Wellenhof, 2001). The VTEC thus calculated corresponds to the coordinates of IPP at each epoch of pass of the respective GPS satellite. Since, the data at the satellite elevation angle lower than $30^{\circ}$ may be corrupted due to multi-path and higher horizontal ionospheric gradients, such data has been excluded from the presentation. The GPS satellites are designated by a pseudorandom number (PRN). We have observed that six satellites with PRNs 1, 14, 15, 18, 22, and 25 were in sight from both the stations during the period (from 06:00-12:00 UT), when the geomagnetic storm commenced on 15 May. However, we are presenting the results from two representative PRNs, 14 and 22 , for both the stations. These cover the main features of VTEC observed by other PRNs as well. Figure $3 a$ and $b$ gives the VTEC variations as observed for PRNs 14 and 22, respectively, from Udaipur. Similar results for Hyderabad are given in Fig. 4a and $b$ and cover the local daytime on 15 May 2005. The bottom panels in Figs. 3 and 4 give two types of VTEC curves. The solid black-continuous curve shows the VTEC observed on 15 May. The blue dotted curve with 1sigma vertical bars on each epoch of observation shows the 


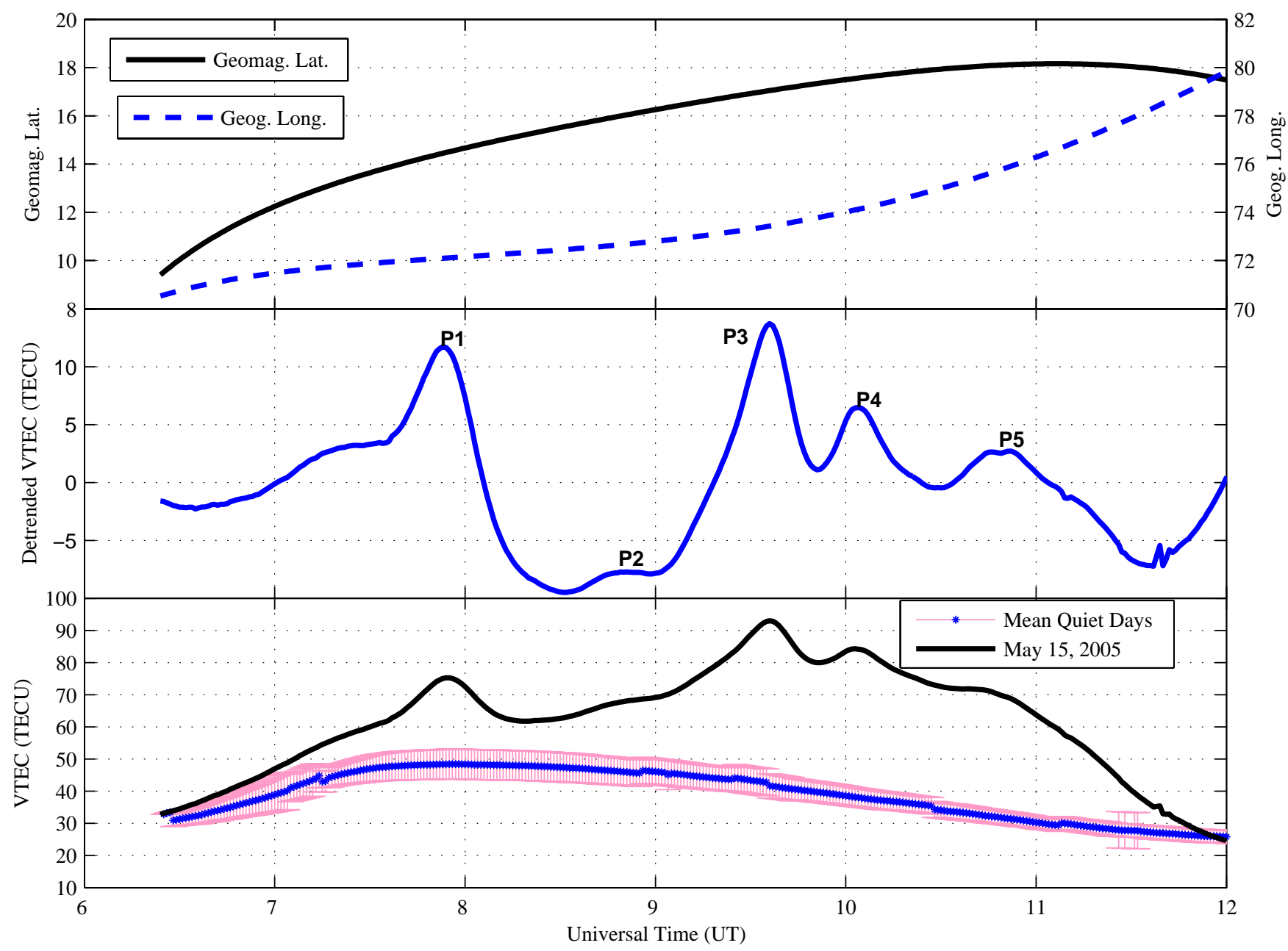

Fig. 3a. VTEC observations from Udaipur for PRNs 14. The VTEC curve on 15 May 2005 (black solid) is shown in comparison with the mean VTEC (blue dotted) in the bottom panel. Vertical bars (magenta) of $1 \sigma$ on mean VTEC curve represent the standard deviation for estimated mean. Middle panel shows the detrended VTEC obtained by detrending the VTEC of 15 May with a polynomial fit. The Uppermost panel in the figure shows the Geomag. Lat. (left ordinate-black curve) and Geog. Long. (right ordinate-blue dashed curve) for the IPPs for the pass of GPS satellite, respectively.

mean VTEC values of the quiet days of May 2005 for the same PRN. The mean VTEC curves exhibit smooth variations with respect to time, while the satellites cover a range of latitudes and longitudes. The middle panels of the Figs. 3 and 4 give the detrended VTEC values obtained from the VTEC values of 15 May. Detrending has been achieved by fitting a polynomial to the VTEC curves of 15 May. This smooth polynomial has been subtracted from the VTEC variations of 15 May to get the detrended VTEC variations. The detrended VTEC has been used to highlight the effect of the storm on 15 May. The most appealing features of VTEC on storm day are the formation of multiple peaks and wave-like features. These features have been very well brought out by the detrended VTEC in the middle panels. We have highlighted the peaks in the detrended VTEC by enumerating them in their order of temporal occurrence. The corresponding peaks are P1 through P5. We will discuss about the time of appearance of each peak in the following subsections. The top panels in the Figs. 3 and 4 give the locations of the IPPs in terms of Magnetic Latitude (scale on left ordinate, continuous black curve) and the Geographic Longitude (scale on right ordinate, broken blue curve) for each epoch of observation. It is worth mentioning here that the GPS satellites are slow east-west moving satellites and the VTEC observations should always be looked at the location of IPPs in space and time.

\subsubsection{Observation from Udaipur GPS station}

Figure $3 \mathrm{a}$ and $\mathrm{b}$ gives the VTEC variations on 15 May as observed from Udaipur. The bottom panels of both the figures 


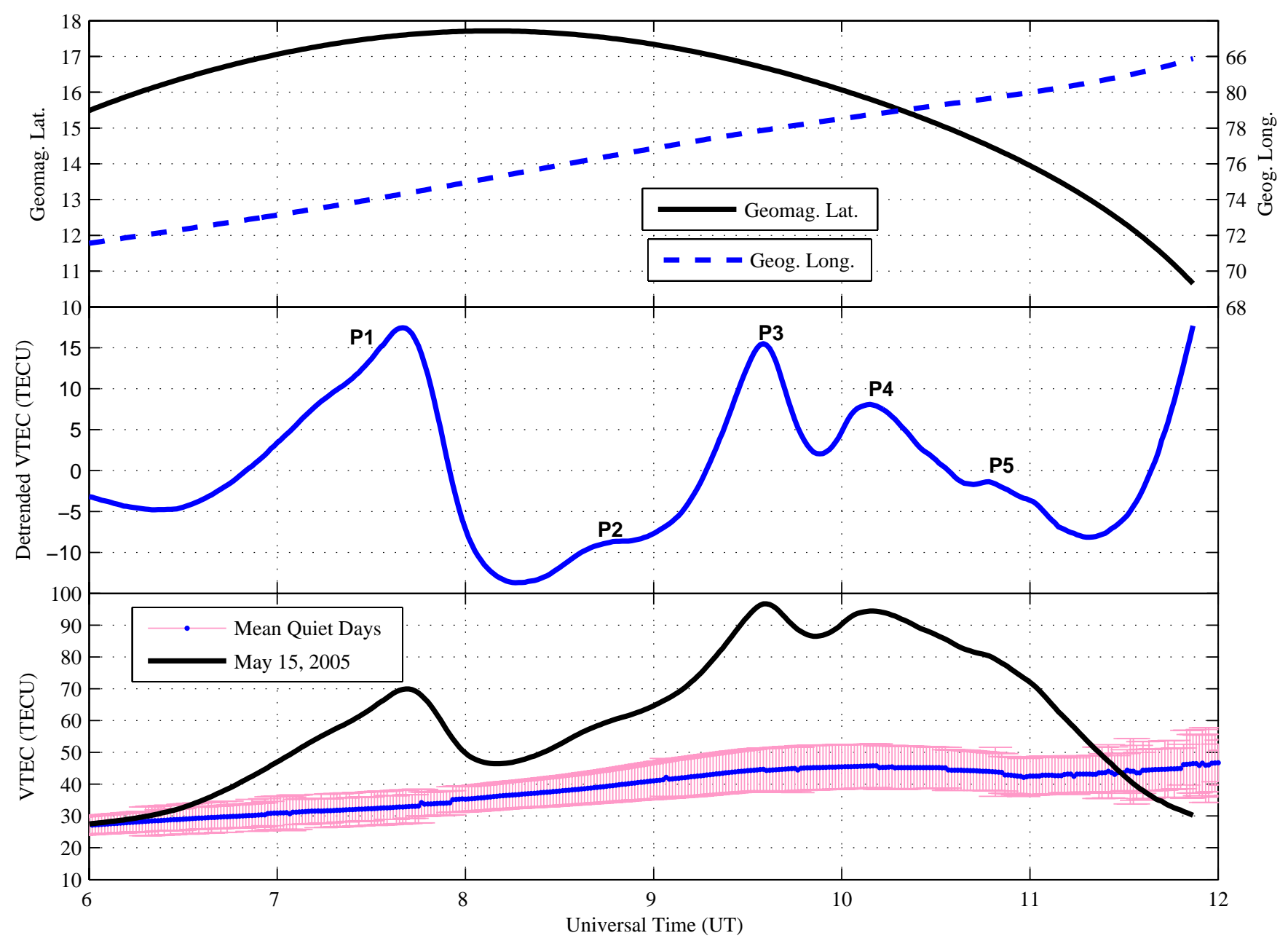

Fig. 3b. VTEC observations from Udaipur for PRNs 22. Rest is same as Fig. 3a.

show large differences between the mean VTEC curves and the VTEC curves of 15 May for both the PRNs 14 and 22. As evident from the top panels of Fig. 3a and b, each PRN has covered a large range of magnetic latitudes and longitudes, from about $10^{\circ} \mathrm{N}$ to $18^{\circ} \mathrm{N}$ in latitudes and from $70^{\circ} \mathrm{E}$ to $80^{\circ} \mathrm{E}$ in longitudes. Thus each satellite PRN 14 and 22, covers the EIA region in Indian zone. The bottom panels of the figures clearly reveal that the mean VTEC curves for either PRN are smooth and that the maximum mean VTEC value is about 50 TECU during the quiet periods. In Fig. 3a, a discernible maximum occurs around 10:00 UT and in Fig. 3b it is around 08:00 UT, when the satellites pass near, or, through the crest region of the EIA. This difference in time, when maximum VTEC is observed for the two PRNs, is due to different latitude zones that the two satellites cover.

Compared to the mean VTEC, the VTEC on 15 May is, in general, enhanced after 06:00 UT with a maximum in the range 90-95 TECU. The most appealing features of storm day VTEC are the multiple peaks and wave-like features. It can be seen from Fig. 3a and b that, on 15 May, the VTEC values are higher than the mean VTEC throughout 06:0012:00 UT. The VTEC increases up to about 07:50 UT and then starts decreasing. The decrement in VTEC is seen up to 08:15-08:30 UT. Thus, a peak in VTEC formed around 07:50 UT. The detrended VTEC shown in the middle panels of Fig. 3a and b, clearly bring out this feature. This peak is has been denoted by P1. The coordinates corresponding to the peak P1 can be ascertained from the top panels of Fig. 3a and $b$ for PRNs 14 and 22, respectively. In terms of (MLAT, GLONG) pairs, the location of $\mathrm{P} 1$ is about $\left(14.5^{\circ} \mathrm{N}, 72^{\circ} \mathrm{E}\right)$ for PRN 14 and $\left(17.5^{\circ} \mathrm{N}, 72^{\circ} \mathrm{E}\right)$ for PRN 22. The coordinates of P1 for the two PRNs imply simultaneous formation of the peak on the same longitude sector, but at different latitudes. Formation of P1 at the same time (07:50 UT) but at different latitudes refers to the common mechanism that is operational for the formation of this peak. The other peaks, P2 through P5 are formed at 08:55 UT, 09:35 UT, 10:10 UT and 10:55 UT, respectively, as shown in the middle panels of both Fig. $3 a$ and $b$. 


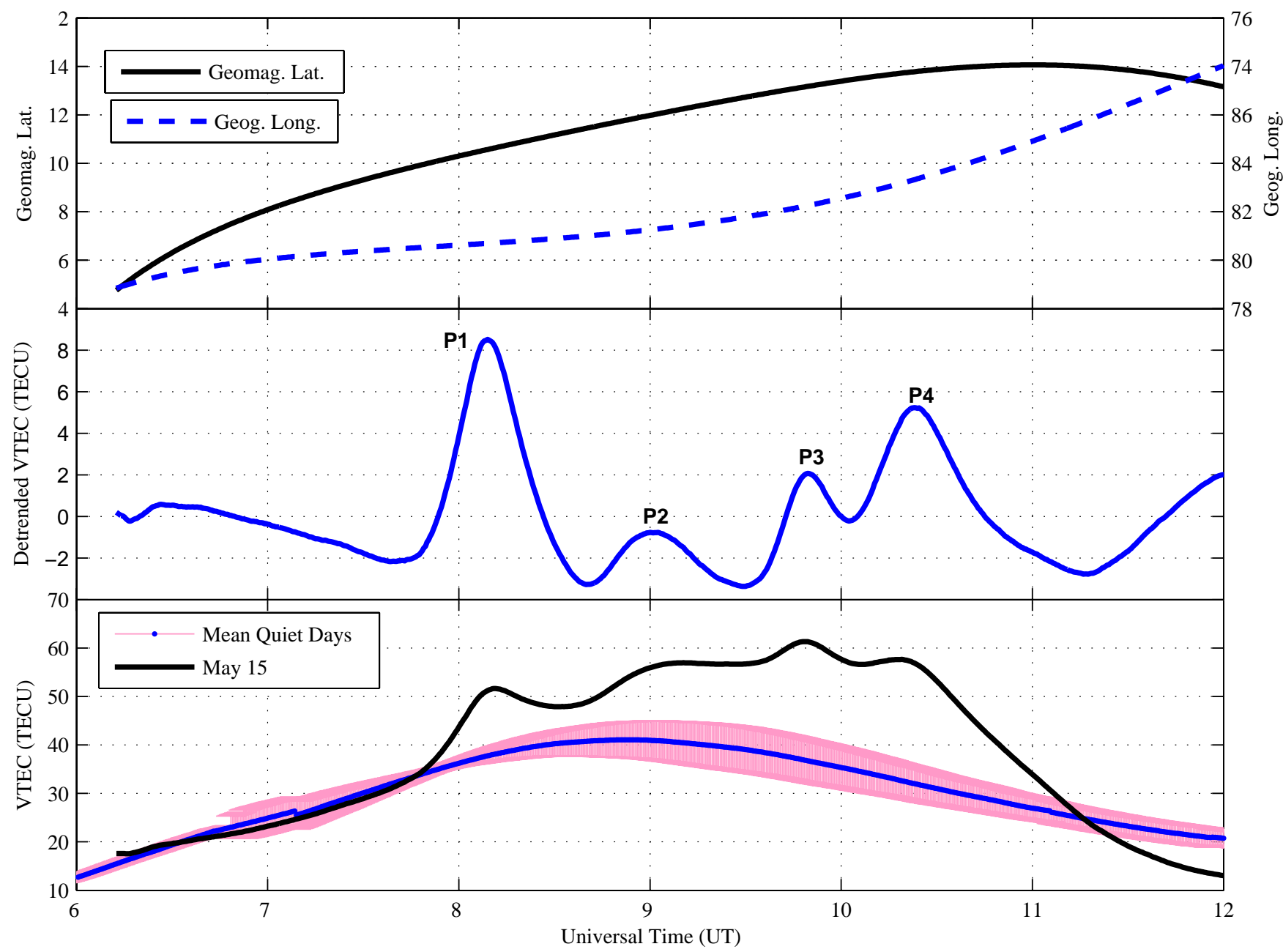

Fig. 4a. VTEC observations from Hyderabad for PRNs 14. Rest is the same as Fig. 3a.

\subsubsection{Observations from Hyderabad GPS station}

Figure $4 \mathrm{a}$ and $\mathrm{b}$ gives the observations on 15 May from Hyderabad GPS station for the same PRNs 14 and 22. The VTEC variations, as seen from Hyderabad, appear to be similar to the ones seen from Udaipur. The wave like features in VTEC are again observed. However, there are a few differences, in terms of range of latitudes and longitudes covered by the satellites and the details of temporal variations of VTEC. As is evident from Fig. 4a and b, the PRNs have covered a large range of (magnetic) latitudes and longitudes, from $02^{\circ} \mathrm{N}$ to $12^{\circ} \mathrm{N}$ and $75^{\circ} \mathrm{E}$ to $84^{\circ} \mathrm{E}$. It should be noted that this area, covered by PRNs 14 and 22 from Hyderabad, comes under the equator-ward boundary of EIA in the Indian zone. The longitudinal coverage is displaced eastward compared to the coverage from Udaipur. Effectively, the combined observations from Udaipur and Hyderabad provide the MLAT coverage from $02^{\circ} \mathrm{N}$ to $18^{\circ} \mathrm{N}$ and the longitudinal coverage from $70^{\circ} \mathrm{E}$ to $84^{\circ} \mathrm{E}$. Therefore, these observations justify the interpretations that have been given in a later section.

\subsection{Ionogram data from New Delhi}

The ionograms were recorded at New Delhi (Geog. Lat. $28.6^{\circ} \mathrm{N}$, Geog. Long. $77.2^{\circ} \mathrm{E}$ ) with a $15 \mathrm{~min}$ time resolution. Two parameters of interest have been extracted from the ionograms. The first parameter is the critical frequency of F2-layer i.e. $f o \mathrm{~F} 2(\mathrm{MHz})$, that gives the temporal variations in the F-region electron density and the second is the $h m \mathrm{~F} 2(\mathrm{Km})$ obtained from true height analysis, for inferring the height variations. Bittencourt and Abdu (1981) have emphasized that during daytime, the variations in the virtual height of F-layer $\left(h^{\prime} F\right)$ may not provide critical information about the vertical motions of the F-layer. Therefore, we have used the height of the F2-layer, corresponding to the maximum density $(h m \mathrm{~F} 2)$ to examine the vertical motions of the F-layer. Figure 5 provides these observations on 14 May 


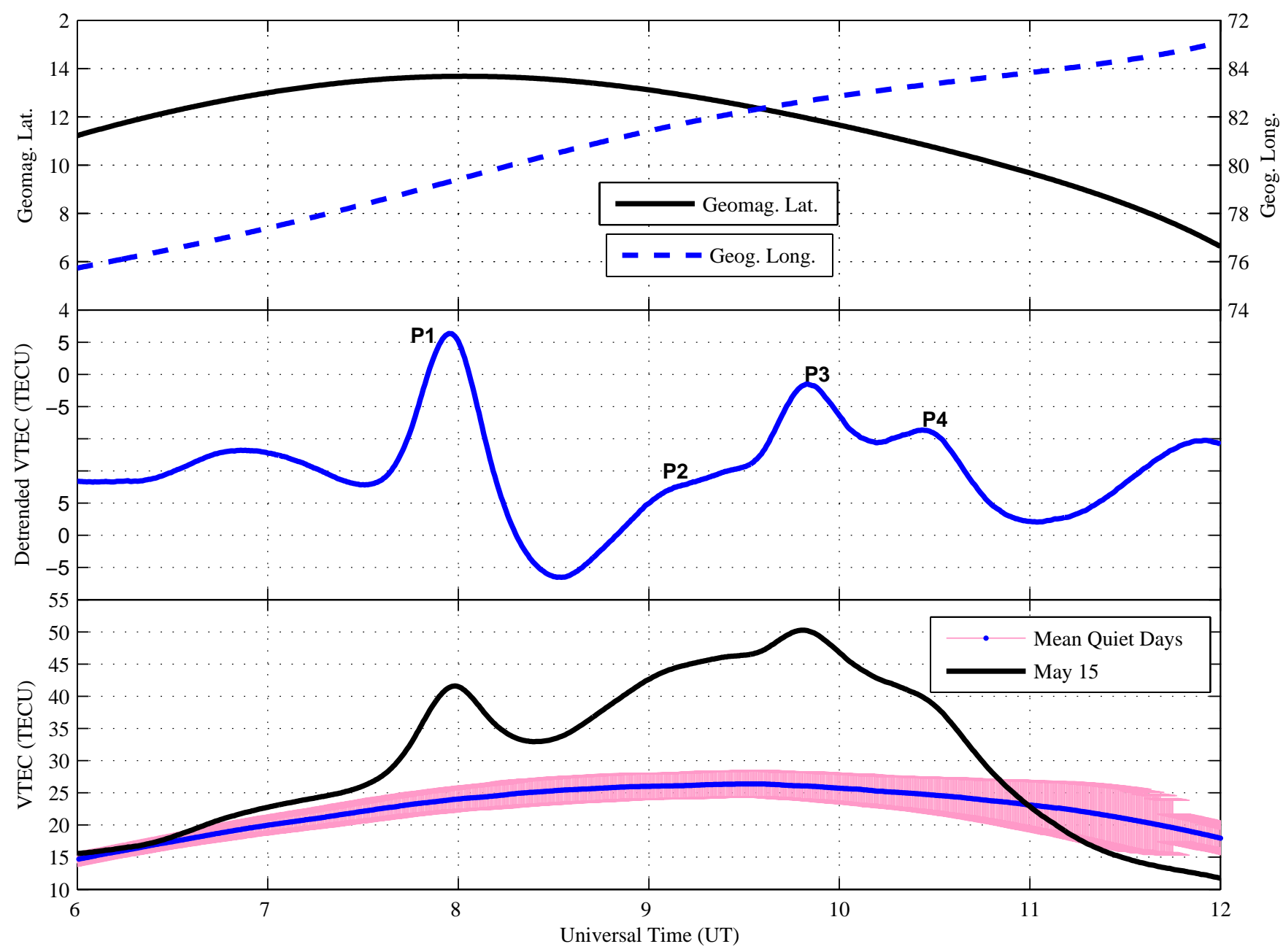

Fig. 4b. VTEC observations from Hyderabad for PRNs 22. Rest is same as Fig. 3a.

and 15 May 2005. Observations on 14 May serve as quiet time base values for comparison with storm time values on 15 May. Variations of $f o F 2$ are given in the bottom panel and that of $h m \mathrm{~F} 2$ in the top panel of Fig. 5, for 14 May (triangles with blue line) and 15 May (stars with red line), respectively. The lower abscissa shows the time in IST (Indian Standard Time $=\mathrm{UT}+05: 30 \mathrm{~h}$ ), while the uppermost abscissa shows the time in UT. The $h m \mathrm{~F} 2$ variation on 14 May at New Delhi reveals that the F-layer rises up after sunrise and reaches an altitude of about $420 \mathrm{~km}$ around noon. Thereafter, it gradually comes down to about $300 \mathrm{~km}$ near sunset. The foF2 on 14 May starts increasing gradually after sunrise and has a broad maximum past $1400 \mathrm{~h}$ and declines after $1900 \mathrm{~h}$.

On 15 May, a sudden anomalous increment in $h m \mathrm{~F} 2$ around 06:00 UT is clearly visible. The increment in the $f_{o} \mathrm{~F} 2$ followed that in the $h m \mathrm{~F} 2$, though delayed by more than one hour. The $h m \mathrm{~F} 2$ remained above $430 \mathrm{~km}$ up to 07:40 UT, while the foF 2 increased up to $14 \mathrm{MHz}$ until this time. Then a decrease in the $h m F 2$ from about 07:30 UT, was simultaneously followed by a sudden drop in the $f o \mathrm{~F} 2$, up to 08:30 UT. Again, a large increment in the $h m \mathrm{~F} 2$ started at 08:50 UT and peaked at around 09:10 UT. Thereafter, the $h m \mathrm{~F} 2$ decreased continuously to around 12:00 UT. Whereas, the $f_{o} \mathrm{~F} 2$ showed consistent increments with small steps from 08:50 UT up to 11:30 UT and sharply decreased thereafter. Conclusively, the peaks in the $h m \mathrm{~F} 2$ occurred at around 06:00 UT and 08:50 UT. Similarly, two peaks in the foF2 occurred, one at around 07:30 UT and another between 09:30 to 11:30 UT. The ionosonde data has provided important information about the daytime F-layer height variations and subsequent follow-ups in low latitude electron density.

\section{Results and discussion}

Results on variations in TEC in the low latitude Indian zone, following a geomagnetic storm on 15 May 2005, have been presented. These observations have been substantiated by 


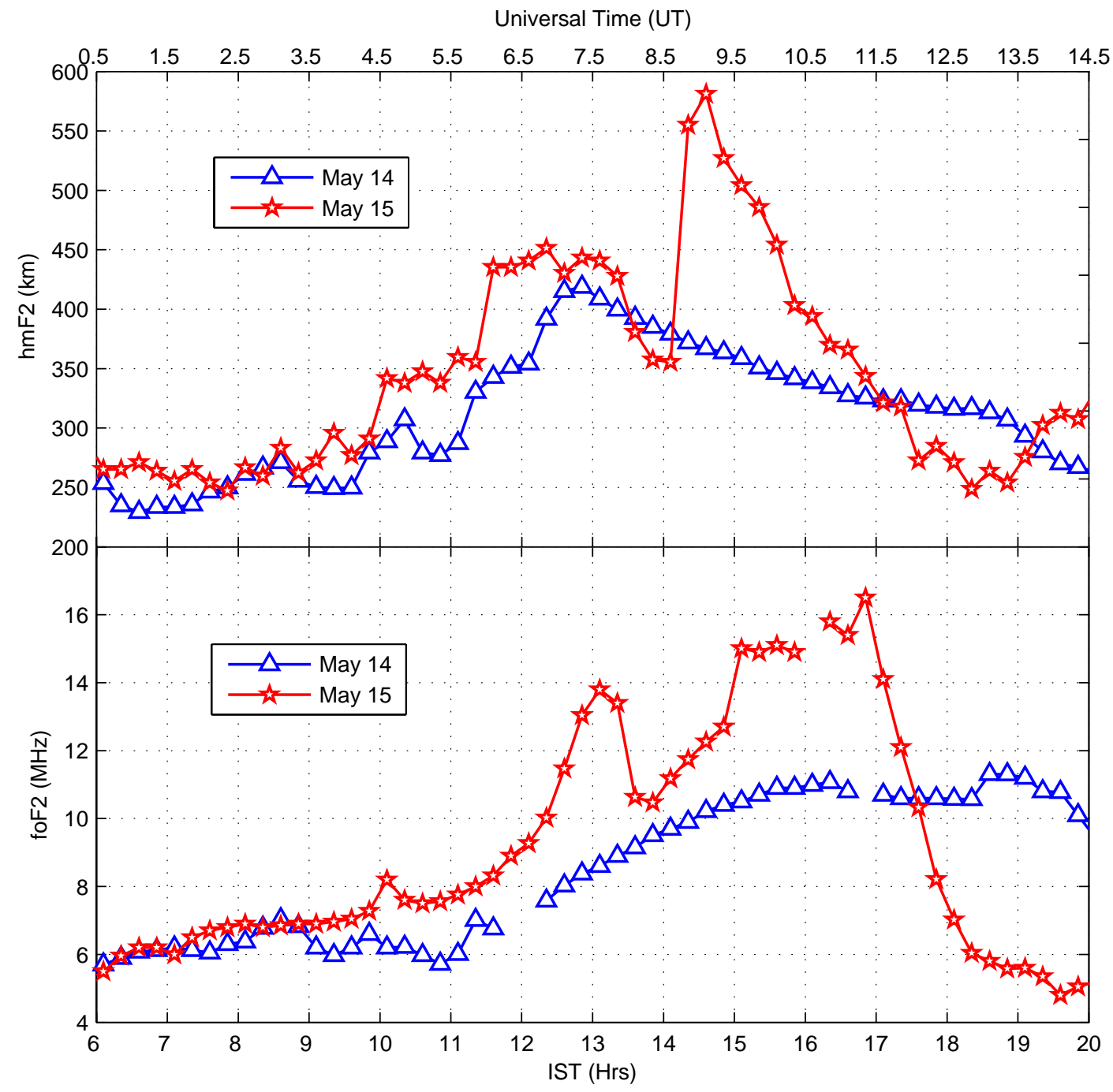

Fig. 5. Ionosonde data from New Delhi for the period of 14 and 15 May 2005. Variation of $h m \mathrm{~F} 2(\mathrm{~km})$ are shown in the upper panel and that of $f \circ \mathrm{F} 2(\mathrm{MHz})$ are shown in lower panel, with respect to Indian Standard Time (IST) on lowermost abscissa and UT on uppermost abscissa. Blue triangle markers represent values of parameters on 14 May and red star markers with red line represent that on 15 May 2005.

solar wind data, the ground-based magnetometers data from Alibag and Tirunelveli and ionosonde data from New Delhi. Gross features of the geomagnetic storm have been identified. The main phase of this storm commenced at around 06:00 UT on 15 May 2005 (Fig. 1) and the high latitude convection electric field penetrated to the equatorial and low latitudes in the Indian sector, is obvious from the Fig. 2. These observations provide us with sufficient inputs to discuss the high latitude penetration electric field associated with sudden southward and then northward turning of IMF- $B_{z}$ on 15 May 2005. The temporal responses of the storm-time phenomena and their ionospheric signatures would be discussed hereafter.

\subsection{Composite effects of sudden southward and north- ward turning of IMF- $B_{z}$}

The IMF- $B_{z}$ suddenly turned southward at 06:00 UT and after a few minutes, it turned northward at 06:15 UT (see Fig. 1). Then it recovered to zero level at 09:00 UT and went up and remained further northward until 11:00 UT. We wish to emphasize the response of the perturbation electric field associated with transient south and northward turning of the IMF- $B_{z}$ at around 06:00 UT and 06:15 UT. Figure 2 shows that similar fluctuations occurred in $\left(H_{\mathrm{TIR}}-H_{\mathrm{ABG}}\right)$, and, hence, in the direction of zonal perturbation electric field in equatorial and low latitudes. Sastri et al. (1992a, b) and Kikuchi et al. (1996, 2008) have reported the transient perturbation electric fields of mixed polarity over the equator. 
Sastri et al. (1992a, b) have interpreted the reversals in the F-region vertical drifts over the equator in ionosonde data as signatures of PP electric field, whereas, Kikuchi et al. have used the magnetometer data. In our case, the sudden polarity reversals in IMF- $B_{z}$ and in the magnetometer data do suggest that during this major geomagnetic storm, the composite effect of both the polarities of high latitude electric fields, reached over the dip equator. The effect of these kinds of reversals on the equatorial and low latitude ionospheric processes has been discussed in what follows.

\subsection{Enhancement in background VTEC and the modi- fied fountain effect}

As noted in Sect. 2, the strength of EIA on a given day, greatly depends upon the equatorial F-region vertical $\boldsymbol{E} \times \boldsymbol{B}$ drift. The day-to-day variability in the equatorial F-region vertical drifts and, hence, in strength of the EIA, has been well known (Fejer et al., 2001). In our observations, the vertical bars on the observed quiet time mean VTEC represent the limit of the day-to-day variability on quiet days. Therefore, we treat the mean VTEC of quiet days as mean background VTEC in low latitudes. Figures 3 and 4 and their details mentioned in the last section clearly entail that apart from occurrence of various peaks mentioned, the VTEC on 15 May was, in general, enhanced for about 4-5 h after 06:30 UT. It is also evident from the figures that the VTEC on May 15 is much higher than the limits of vertical bars on mean values for the same duration. Hence, the large departures of VTEC on 15 May from background VTEC may safely be taken as storm effect.

It has been well known that the development of EIA is a slow process and that any perturbation in equatorial vertical drift is observed in the EIA zone density variations after a delay of 3-4 h (Rastogi and Klobuchar, 1990; Balan and Iyer, 1983). The time lag between the maximum equatorial vertical drift and maximization of the EIA in terms of electron density, is caused due to vertical up-lifting of ionization over the dip equator and then diffusion along the field lines, as discussed in Sect. 2 in detail. Since, the mean time of maximization of the daytime anomaly in the Indian sector is around 08:00-09:00 UT (13:00-14:00 IST) for normal EEJ days (Rastogi and Klobuchar, 1990; Balan and Iyer, 1983), the time 06:30 UT corresponds to the initial phase of EIA build up (in the longitudes covered by present observations). The high latitude dawn-to-dusk electric field penetrated simultaneously all over the low and equatorial region at about 06:00 UT. Therefore, any increment over and above the dayto-day variability in the VTEC in the low latitude EIA zone due to the modified fountain effect (enhanced $\boldsymbol{E} \times \boldsymbol{B}$ drift due to PP field), should be present after around $3 \mathrm{~h}$. Thus, the anticipated time to reach such effects in the EIA zone is after 09:00 UT. Also, as noted in Sect. 2, the variations in the quantity $\left(H_{\mathrm{TIR}}-H_{\mathrm{ABG}}\right)$ manifest the variations in the direction of the zonal electric field (positive-eastward). The equa- torial F-region vertical drift would be upward (downward) for eastward (westward) perturbation zonal electric field in the low latitudes. Thus, the equatorial fountain would be enhanced (suppressed) for upward (downward) equatorial Fregion drifts. But, there is no simple answer to the question of how the EIA would be affected quantitatively by such rapid vertical movements of plasma over the equator (see Fig. 2). We could not find any quantitative study on this aspect of low latitude ionosphere. A numerical modeling study of the low latitude ionosphere may answer this question, but is out of the scope of this paper. However, if we follow our observations for the reversal of quantity $\left(H_{\mathrm{TIR}}-H_{\mathrm{ABG}}\right)$ after 06:15 UT, the equatorial perturbation vertical drift should be downward for the duration from 06:15-08:00 UT, then fluctuate up and down until 10:00 UT, and finally return to the normal quiet time level by 12:00 UT. It is clear from our ionospheric observations that the VTEC is enhanced compared to the quiet time background level from 09:00 UT to 11:30 UT. Hence, the effect of the enhanced plasma fountain over equator is observable in low latitudes, but this is not the case with suppressed fountain. The observations of VTEC in low latitudes do not represent decrements due to suppressed fountain. The sudden fall in VTEC after 11:30 UT shall, primarily, be due to local evening hours. Any effect, even though present, might have been buried under the enhancements because of equator-ward TAD's and subsequent F-layer height and density variations. We would discuss it in Sect. 4.4. Although, the occurrence of a small peak P2 at around 08:5009:00 UT in the Figs. 3 and 4 can be explained, based upon the argument that the enhanced fountain effect over the equator might have increased the low latitude TEC by this time. However, we would revisit the interpretation of peak P2 in a later section, to ascertain a better mechanism. Because after 09:00 UT on 15 May, the VTEC in low latitude EIA zone is also affected by equator-ward traveling waves and disturbances, as explained in one of the following sections. Therefore, the effect of sudden excursions in equatorial fountain and, hence, that of penetration electric fields, over the EIA, could not be quantitatively ascertained from our observations, even though all of the most required observable information is with us.

\subsection{Prompt penetration of electric field in low latitudes and occurrence of the peak-P1}

After 06:00 UT, the $h m \mathrm{~F} 2$ over New Delhi increased and the F-layer was held above $430 \mathrm{~km}$ up to 07:40 UT in response to the eastward PP electric field. The $f o \mathrm{~F} 2$ also increased slowly after 06:00 UT, peaking at 07:30 UT. The VTEC in low latitudes started increasing just after 06:30 UT and the peak P1 observed around 07:50-08:00 UT simultaneously in the large MLAT range. As noted in the last section, the combined observations from Udaipur and Hyderabad provide MLAT coverage from $02^{\circ} \mathrm{N}$ to $18^{\circ} \mathrm{N}$ and longitudinal coverage from $70^{\circ} \mathrm{E}$ to $84^{\circ} \mathrm{E}$. All these results show that just 
after the commencement of the main phase of the storm, the entire low latitude ionosphere started responding to the zonal disturbance electric field. Fejer and Scherliess (1995, 1997) and Abdu (1997) have shown that the response of the equatorial and low latitude ionosphere to the geomagnetic storms is strongly time dependent. Recently, it has been again emphasized that the prompt penetration of electric fields to the low and equatorial latitudes generally lasts for about an hour or so (Fejer et al., 2007). In the present case, the dawn-todusk PP electric field is directed eastward during the day and enhanced the low latitude $\boldsymbol{E} \times \boldsymbol{B}$ drift of the ionization. This inference is based on the data from the ionosonde at New Delhi, which showed a sudden rise in $h m F 2$. The electron density enhanced after a time lag. Under the influence of eastward penetration electric field, the vertical drift of the local low latitude F-region plasma is increased. While the production at the lower altitudes continued, the uplift of plasma at higher altitudes, where the recombination rates are much lower, resulted in the increased density. Thus, the entire low latitude ionosphere simultaneously lifted up, followed by enhanced $f_{o} \mathrm{~F} 2$ at New Delhi and enhanced VTEC in a range of low latitudes. This argument may be sufficient to explain the increments observed in all the parameters but not for the formation of peak P1. The peak P1 is formed due to sudden decrements in $h m \mathrm{~F} 2, f o \mathrm{~F} 2$ and VTEC, following the increments. The explanation of sudden decrements in all the parameters is not straightforward. As noted above, the dawnto-dusk penetration field may not last longer than one hour or so. The low latitude F-region is uplifted due to the penetration electric field but descended, once the effect of this field ceased. Then, at lower heights, the electron densities decreased due to higher recombination rates. This is what we have observed. The above case of decrement in electron density is strengthened under penetration of dusk-to-dawn electric field in low latitudes, subsequent to the penetration of dawn-to-dusk directed field. The downward drift due to penetration westward electric field has better facilitated by the normal re-distribution of the plasma of the uplifted F-layer. The $h m \mathrm{~F} 2$ decreased by $10 \mathrm{~km}$ at around 07:00 UT and recovered just before 07:30 UT. After 07:30 UT, there was a sudden and anomalous reduction in $h m \mathrm{~F} 2$ from $450 \mathrm{~km}$ to $350 \mathrm{~km}$ at 08:30 UT. The simultaneous reduction in the $f_{o} \mathrm{~F} 2$ from $14 \mathrm{MHz}$ to $10.5 \mathrm{MHz}$ is also significant. Such decrements support the presence of dusk-to-dawn electric field in the low latitudes. Concurrently this also provides evidence that storm time penetration electric field directly modifies the low latitude ionospheric plasma densities, apart from the low latitude density modifications governed by the plasma fountain over the equator. This is a first-of-its-kind observation reported in the literature, so far. The effect of penetration electric field over the dip equator and the subsequent effects on the EIA have been studied by many authors but, the local response of the low latitude ionosphere has been first time reported in this study.

\subsection{Traveling atmospheric/ionospheric disturbances and occurrence of the peaks P2, P3, P4 and P5}

The observations detailed in Sect. 3 reveal two features in the VTEC after 09:00 UT on 15 May. The first feature is the highly enhanced level of VTEC and the second is the occurrence of various peaks namely P2, P3, P4 and P5. As mentioned in Sect. 4.2, the effects of equatorial F-region perturbed vertical plasma drifts should reach the EIA zone after about 09:00 UT. Since, the rapid switching in the direction of penetration electric field over equator has greatly affected the equatorial vertical drifts, the one to one correspondence of the same in the EIA development may not be clear. However, the initial plasma uplift due to dawn-to-dusk directed penetration field might have strengthened the EIA after 09:00 UT. This conclusion is similar to the ones drawn by Tsurutani et al. (2004) and Huba et al.(2005). While, this may partly contribute to the enhanced levels of VTEC in low latitudes after 09:00 UT, the formation of peaks in VTEC and sustenance of the higher levels until 11:30 UT, necessitate another pertinent mechanism. As we have detailed in Sect. 1, the impulsive high-energy inputs in the high latitudes during the main phase of geomagnetic storms are known to launch the traveling atmospheric disturbances (TADs). These disturbances travel equator ward with high velocities (Bauske and Prolss, 1997) and may result in the uplifting of the Flayer (Millward et al., 1993; Prolss and Ocko, 2000). The New Delhi ionogram data presented in Fig. 5 shows that the $h m \mathrm{~F} 2$ was $350 \mathrm{~km}$ at around 08:40 UT, and then a large and anomalous ascent in $h m \mathrm{~F} 2$ occurred at around 09:00 UT. The $h m \mathrm{~F} 2$ raised by more than $200 \mathrm{~km}$ within a short duration of half an hour between 08:40 UT and 09:10 UT. The maximum in the $h m \mathrm{~F} 2$ occurred at 09:10 UT with a large value of about $580 \mathrm{~km}$. Such a remarkable elevation in the F-layer height within $3 \mathrm{~h}$ of the commencement of the storm main phase, marks a strong presence of the equatorward traveling atmospheric disturbances (TADs) in the low latitudes. The TADs are impulse-like perturbations formed by a superposition of gravity waves, which propagate with high velocity in meridional direction. An average velocity of the TADs can be estimated from the time of the aforementioned elevation in $h m \mathrm{~F} 2$ and the presence of wave-like perturbations in VTEC. The average meridional velocity for traveling disturbances, estimated from the time delay of $3 \mathrm{~h}$ to travel from auroral zone to low latitudes is $\sim 485 \mathrm{~m} / \mathrm{s}$. It has been emphasized that the TADs affect the ionosphere primarily through their equatorward meridional winds, which drag the ionization along the inclined magnetic field lines, higher in altitude. The height of the ionization layer is thus changed and an increase in layer height leads to a positive ionospheric storm if the height dependence of the ionization production and loss is considered. Therefore, an ascent in $h m \mathrm{~F} 2$ at around 09:00 UT followed by the anomalous increments and enhanced level of $f o \mathrm{~F} 2$ after 09:30 UT at New Delhi confirms the effect of TADs in low latitudes (Prolss, 1993; Kirchenghast, 1996). The TADs 
manifest as TIDs in the ionosphere and the effect of TIDs in ionospheric TEC has been observed as increased levels of VTEC. The presence of peak P2 may also be associated with TIDs. However, the detrended VTEC in Figs. 3 and 4, clearly reveal that the peak $\mathrm{P} 3$ and $\mathrm{P} 4$ are more pronounced and may undoubtedly signify the presence of TIDs. We estimated the period of the wave like perturbations from the detrended VTEC information. The period of disturbance found to be around $40-45 \mathrm{~min}$ and is in conformity with recent observations by Tsugawa et al. (2004) and Ding et al. (2007). The detrended VTEC curves show that the wave-like disturbance have diminishing amplitude in time and space. The P3 and P4 in the observations from Udaipur are more enhanced than from Hyderabad. This confirms the modeling results of Balthazor and Moffett (1997) that the amplitude of TADs decreases, as they arrive closer to the dip equator. The same is clear from the mild signatures of peak P5, which have been observed from Udaipur (see Fig. 3), but is missing from the observations from Hyderabad. The TADs in low latitudes support the enhanced levels of VTEC on 15 May after 09:00 UT. The TADs, manifested as TIDs, also seem to explain the sustenance of the enhanced levels in low latitudes until 11:30 UT, which has neither been facilitated by the effect of disturbance electric fields in low latitudes nor by the response of the EIA to them.

\subsection{Effect of the space weather events on position solu- tions provided by GPS}

The position of a GPS receiver/user can be estimated using the GPS signal. Inherent to the position solution are some errors related to satellite orbit, satellite clock, satellite and receiver hardware biases, receiver clock, total electron content and total water content in the line of sight for a satellitereceiver pair (Hoffmann-Wellenhof, 2001). Among the dispersive errors are the line of sight TEC and the hardware differential biases. A satellite based navigation system (SBAS) like WAAS (Wide Area Augmentation Systems) in the USA and the forthcoming GAGAN (GPS aided geo-augmented navigation) in India, monitors GPS satellite signals for the aforementioned errors and then generates correction messages to improve positioning accuracy for users. In equatorial and low latitudes, the day-to-day variability in TEC hinders the accurate position estimates. The maximal variability in TEC encountered in these latitudes all over the globe and hence, in Indian zone because it falls under the northern part EIA. The crest of northern part of EIA lies between $12^{\circ}-16^{\circ}$ MLAT for variable solar activity. Therefore, even the dayto-day TEC corrections for SBAS are highly variable in the Indian zone. The situation worsens in the EIA zone when the events like equatorial spread-F (ESF) and geomagnetic storms occur. Dashora and Pandey (2005) first reported the effects of ESF on GPS-TEC, in the Indian zone. The ESF, being post-evening phenomena, do greatly affect the nighttime ionospheric correction capability for any SBAS. The
TEC depletions of about 20-25 TECU and the ionospheric scintillations associated with the ESF affect the phase and amplitude of the GPS signal. It has been a big challenge so far to predict the occurrence of ESF and the temporal corrections thereof. We wish to emphasize here the similarity with the space weather events. They originate from the sun and subsequent to the occurrence of geomagnetic storms and sub-storm, do affect the ionosphere on varied time scales from hours to days, known as ionospheric storms. The effects of geomagnetic storm on GPS-TEC are comparable and sometimes more grievous than ESF, because of their independence in temporal occurrence with regards to local time. We have presented the results of a daytime positive ionospheric storm followed by a major geomagnetic storm in this paper in terms of GPS-TEC. The results show that the rapid variations of about 15-20 TECU occurred in the VTEC on 15 May, compared to quiet time levels, whereas, the peak values of VTEC were about 95-100 TECU on storm day. A TECU corresponds to a vertical delay of $0.16 \mathrm{~m}$ on L1 frequency and hence the ionospheric error extended to $\sim 16 \mathrm{~m}$ on 15 May. The rapid and large temporal and spatial variations in the ionospheric error are more threatening than the absolute errors. Henceforth, in reference to the variations in TEC on 15 May 2005, there is a great need to understand the variability of low latitude TEC in order to mitigate the ionospheric errors for the user of any SBAS system. Such corrections are stringent for the more precise aviation requirements based on any SBAS, in the EIA zone. Our observation and study highlights the urgent need for more rigorous efforts in understanding the response of the equatorial and low latitude ionosphere during the Space Weather events.

\section{Conclusions}

We have studied an interplanetary event that caused a major geomagnetic storm on 15 May 2005. It has been noted that the interplanetary disturbances originating from the Sun, greatly altered the near-earth space weather conditions on a large temporal and spatial scale. The response of the coupled magnetosphere-ionosphere-thermosphere system during the event greatly departed from quiet time conditions. The main results and observations that we wish to illustrate from this study are as follows:

1. The storm commenced in the early morning hours in Indian longitude sector and the ionospheric effect of the penetration of electric field associated with SSC could not be ascertained from our observations.

2. The main phase of the storm commenced at 06:00 UT, when the IMF- $B_{z}$ suddenly turned southward and dropped to $-45 \mathrm{nT}$. Subsequently, the dawn-to-dusk electric field associated with high latitude convection (Kikuchi, 1996), penetrated simultaneously to equatorial and low latitudes. The same has been evident by 
fluctuations in the magnetometer data. The lowest value of SYM-H index was $-305 \mathrm{nT}$ at around 08:20 UT on 15 May and categorized it as a major geomagnetic storm.

3. The IMF- $B_{z}$ dropped to $-45 \mathrm{nT}$, but did not remain steady at that level for a long period. The sudden recovery (northward transition) in IMF- $B_{z}$ began a few minutes after the maximum negative excursion, however, it remained southward (below zero level) up to about 09:00 UT.

4. The magnetometer data from the Indian zone was evident in that the high latitude convection electric field of both polarity (eastward and westward), penetrated to equatorial and low latitudes, following the reversals in the IMF- $B_{z}$. Anderson et al. (2002) have utilized the magnitude of the $\Delta H$ for estimating the $\boldsymbol{E} \times \boldsymbol{B}$ drift over the equator. Since, the effect of the disturbance current is enhanced in $\left(\Delta H_{\mathrm{TIR}}-\Delta H_{\mathrm{ABG}}\right)$ but that of the external field may not be well represented (especially in low latitudes), we have utilized the $\left(\Delta H_{\mathrm{TIR}}-\Delta H_{\mathrm{ABG}}\right)$ for deducing merely the direction of the penetration electric field and not the magnitude of the $\boldsymbol{E} \times \boldsymbol{B}$ drift, unlike others (Anderson et al., 2002).

5. The concurrent enhancement in low latitude VTEC and $f_{o F} 2$ after 06:30 UT, in response to the dawn-to-dusk penetration electric field, has been attributed to local low latitude response to the dawn-to-dusk penetration electric field. The peak P1 formed because the increments in the VTEC and foF2 were preceded by sudden decrements at around 07:50-08:10 UT. The decrements have been attributed to, either the termination of the penetration eastward electric field, or to the penetration of westward (dusk-to-dawn) electric field to low latitudes (Kelley et al., 1979). These decrements in low latitude EIA zone have not been related to suppression of equatorial fountain because a delay of less than two hours does not justify the relevance.

6. The presence of TADs at low latitude has been evident by anomalous ascent of $h m \mathrm{~F} 2$ by $200 \mathrm{~km}$ within half an hour duration at around 09:00 UT. The enhanced levels of VTEC and foF2 after 09:00 UT on 15 May, compared to the quiet background VTEC, have been attributed to the uplift of F-layer at low latitudes, in response to meridional winds associated with equator-ward TADs. An increase in layer height lead to a positive ionospheric storm under consideration of the height dependence of the ionization production and loss during daytime. Our observations are conform with model results of Balthazor and Mofett (1997). The results show that, after the commencement of the main phase of the storm, the TADs arrived in low latitudes when the extra ionization, due to enhanced fountain over the equator, was reached. Thus the development of the EIA and the effect of equator-ward TIDs in TEC competed to produce the net variations in TEC in low latitudes.

7. The average velocity of TADs obtained is $\sim 485 \mathrm{~m} / \mathrm{s}$ and the period of wave-like disturbances in VTEC is $\sim 40$ $45 \mathrm{~min}$. Both of the observations are in conformity with Tsugawa et al. (2004) and Ding et al. (2007).

8. We present the first results of the effect of geomagnetic storm that occurred on 15 May 2005 on GPS-TEC from the Indian zone. We have emphasized that the TEC variations in low latitudes during geomagnetic storms pose a serious threat to satellite based navigation systems. There is an urgent need to begin the GPS network based studies in Indian zone for better temporal and spatial coverage during such events. Our future plan is to use such network data for better quantification of the results and inclusion of low latitude ionospheric models to study the individual effects of various processes in the coupled system.

9. There have been many attempts to model the ionospheric responses to geomagnetic storms (Fejer and Scherliess, 1995, 1997; Huba et al., 2005; Huang et al., 2005; Maruyama et al., 2005, 2007, and references therein). The observations presented here will provide more inputs for better reproduction of the responses of low latitude electrodynamics during space weather events, especially for the temporal occurrence of effects of penetration electric fields and TADs on low latitude TEC.

Acknowledgements. We thank the ACE SWEPAM and MAG instrument teams and the ACE Science Center for providing the ACE data. We acknowledge the International GNSS Service (IGS) for providing the GPS data. The SYM-H data are provided by the World Data Center for Geomagnetism at Kyoto University, Japan. The GSV 4004A GPS receiver and TEC monitor at Udaipur was purchased through the grants from University Grants Commission, New Delhi under the DRS program and the X plan. R. Pandey acknowledges the ISRO-RESPOND for partial support of the work.

Topical Editor M. Pinnock thanks J.-H. Sastri and H. Chandra for their help in evaluating this paper.

\section{References}

Abdu, M. A.: Major phenomena of the equatorial ionospherethermosphere system under disturbed conditions, J. Atmos. Solor-Terr. Phys., 59(13), 1505-1519, 1997.

Afraimovich, E. L., Kosogorov, E. A., Leonovich, L. A., Palamartchouk, K. S., Perevalova, N. P., and Pirog, O. M.: Determining parameters of large-scale traveling ionospheric disturbances of auroral origin using GPS-arrays, J. Atmos. Sol. Terr. Phys., 62, 553-565, 2000.

Anderson, D., Anghel, A., Yumoto, K., Ishitsuka, M., and Kudeki, E.: Estimating daytime vertical $\boldsymbol{E} \times \boldsymbol{B}$ drift velocities in the equatorial F-region using ground-based magnetometer observations, 
Geophys. Res. Lett., 29(12), 1596, doi:10.1029/2001GL014562, 2002.

Anderson, D., Anghel, A., Chau, J., and Veliz, O.: Daytime vertical $\boldsymbol{E} \times \boldsymbol{B}$ drift velocities inferred from ground-based magnetometer observations at low latitudes, Space Weather, 2, S11001, doi:10.1029/2004SW000095, 2004.

Anderson, D., Anghel, A., Chau, J. L., and Yumoto, K.: Global, low-latitude, vertical $\boldsymbol{E} \times \boldsymbol{B}$ drift velocities inferred from daytime magnetometer observations, Space Weather, 4, S08003, doi:10.1029/2005SW000193, 2006.

Anghela, A., Anderson, D., Maruyama, N., Chau, J., Yumoto, K., Bhattacharyya, A., and Alex, S.: Interplanetary electric fields and their relationship to low-latitude electric fields under disturbed conditions, J. Atmos. Solor-Terr. Phys., 69, 1147-1159, 2007.

Balan, N. and Iyer, K. N.: Equatorial anomaly in ionospheric electron content and its relation to dynamo currents, J. Geophys Res., 88, 10259-10262, 1983.

Balthazor, R. L. and Moffett, R. J.: A study of atmospheric gravity waves and travelling ionospheric disturbances at equatorial latitudes, Ann. Geophys., 15, 1048-1056, 1997, http://www.ann-geophys.net/15/1048/1997/.

Basu, Su., Basu, S., Valladares, C. E., Yeh, H.-C., Su, S.-Y., Mackenzie, E., Sultan, P. J., Aarons, J., Rach, F. J., Doherty, P., Groves, K. M., and Bullett, T. W.: Ionosphearic effects of major magnetic storms during the interational space period of september and october 1999: GPS obervations, VHF/UHF scintillations, and in situ density structurs at middle and equatorial latitudes, Geophys. Res. Lett., 106(12), 30389-30413, 2001.

Bauske R. and Prolss, G. W.: Modelling the ionospheric response to travelling atmospheric disturbances, J. Geophys. Res., 102, 14555-14562, 1997.

Bittencourt, J. A. and Abdu, M. A.: A theoretical comparison between apparent and real vertical ionization drift velocities in the equatorial F region, J. Geophys. Res., 86, 2451-2454, 1981.

Blanc, M. and Richmond, A. D.: The ionospheric disturbance dynamo, J. Geophys. Res., 85, 1669-1686, 1980.

Blewitt, G.: An Automatic Editing Algorithm for GPS Data, Geophys. Res. Lett., 17(3), 199-202, 1990.

Buonsanto, M. J.: Ionospheric storms: A review, Space Sci. Rev., 88, 563-601, 1999.

Chandra, H. and Rastogi, R. G.: Geomagnetic storm effects on ionospheric drifts and the equatorial Es over the magnetic equator, Ind. J. Radio Space Phys., 3, 332-336, 1974.

Dashora, N. and Pandey, R.: Observations in equatorial anomaly region of total electron content enhancements and depletions, Ann. Geophys., 23, 2449-2456, 2005,

http://www.ann-geophys.net/23/2449/2005/.

Dashora, N. and Pandey, R.: Variations In Total Electron Content Near The Crest of The Equatorial Ionization Anomaly During the November 2004 Geomagnetic Storm, Earth Planets Space, 59, 127-131, 2007a.

Dashora, Nirvikar and Pandey, R.: GPS Data Post-Processing Methods for Un-differenced Receivers Located near the crest of EIA, International Beacon Satellite Symposium, Boston, USA, 2007b.

Ding, F., Wan, W., Ning, B., and Wang, M.: Large-scale traveling ionospheric disturbances observed by GPS total electron content during the magnetic storm of 29-30 October 2003, J. Geophys.
Res., 112, A06309, doi:10.1029/2006JA012013, 2007.

Fejer, B. G., Gonzales, C. A., Farley, D. T., Kelley, M. C., and Woodman, R. F.: Equatorial electric fields during magnetically disturbed periods: 1. Effect of the interplanetary magnetic field, J. Geophys. Res., 84, 5797-5802, 1979.

Fejer, B. G.: Low latitude electrodynamic plasma drifts: a review, J. Atmos. Terr. Phys., 53, 677-693, 1991.

Fejer, B. G. and Scherliess, L.: Time dependent response of equatorial ionospheric electric fields to megnetospheric disturbances, Geophys. Res. Lett., 22, 851-854, 1995.

Fejer, B. G. and Scherliess, L.: Empirical models of storm-time equatorial zonal electric fields, J. Geophys. Res., 102, $24047-$ 24056, 1997.

Fejer, B. G. and Scherliess, L.: On the variability of equatorial F-region vertical plasma drifts, J. Atmos. Solar-Terr. Phys., 63, 893-897, 2001.

Fejer, B. G., Jensen, J. W., Kikuchi, T., Abdu, M. A., and Chau, J. L.: Equatorial Ionospheric Electric Fields During the November 2004 Magnetic Storm, J. Geophys. Res., 112, A10304, doi:10.1029/2007JA012376, 2007.

Forbes, J. M.: The equatorial electrojet, Rev. Geophys. Space Phys., 19, 469-504, 1981.

Foster, J. C. and Rideout, W.: Midlatitude TEC enhancements during the October 2003 superstorm, Geophys. Res. Lett., 32, L12S04, doi:10.1029/2004GL021719, 2005.

Gonzales, C. A., Kelley, M. C., Behnke, R. A., Vickrey, J. F., Wand, R., and Holt, J.: On the latitudinal variations of the ionospheric electric field during magnetospheric disturbances, J. Geophys. Res., 88, 9135-9144, 1983.

Gonzalez, W. D., Joselyn, J. A., Kamide, Y., Kroehl, H. W., Rostoker, G., Tsurutani, B. T., and Vasyliunas, V. M.: What is a geomagnetic storm?, J. Geophys. Res., 99, 5771-5792, 1994.

Gurtner, W.: RINEX: The Receiver-Independent Exchange Format, GPS World, vol. 5, nr. 7, July 1994.

Hines, C.O.: Internal Atmospheric Gravity Waves at ionospheric heights, Can. J. Phys., 38, 1441-1481, 1960.

Hines, C. O.: The upper atmosphere in motion, Geophysical Monograph, American Geophysical Union, 1974.

Ho, C. M., Mannucci, A. J., Sparks, L., Pi, X., Lindqwister, U. J., Wilson, B. D., Iijima, B. A., and Reyes, M. J.: Ionospheric total electron content perturbations monitored by the GPS global network during two northern hemisphere winter storms, J. Geophys. Res., 103(A11), 26409-26420, doi:10.1029/98JA01237, 1998.

Hocke, K. and Schlegel, K.: A review of atmospheric gravity waves and travelling ionospheric disturbances: 1982-1995, Ann. Geophys., 14, 917-940, 1996, http://www.ann-geophys.net/14/917/1996/.

Hofmann-Wellenhof, B., Lichtenegger, H., and Collins, J.: Global Positioning System: Theory and Practice, Springer-Verlag, 2001.

Huang, C.-S., Foster, J. C., and Kelley, M. C.: Long-duration penetration of the interplanetary electric field to the low-latitude ionosphere during the main phase of magnetic storms, J. Geophys. Res., 110, A11309, doi:10.1029/2005JA011202, 2005.

Huba, J. D., Joyce, G., Sazykin, S., Wolf, R., and Spiro, R.: Simulation study of penetration electric field effects on the lowto mid-latitude ionosphere, Geophys. Res. Lett., 32, L23101, doi:10.1029/2005GL024162, 2005.

Jakowski, N., Schlter, S., and Sardn, E.: Total electron content of the ionosphere during the geomagnetic storm on 10 January 
1997, J. Atmos. Solar-Terr. Phys., 61(3-4), 299-307, 1999.

Jing, N. and Hunsucker, R. D.: A theoretical investigation of sources of large and medium scale atmospheric gravity waves in the auroral oval, J. Atmos. Terr. Phys., 55, 1667-1679, 1993.

Kelly, M. C., Fejer, B. G., and Gonzalez, C. A.: An explanation for anomalous equatorial ionospheric electric fields associated with the northward turning of the interplanetary magnetic field, Geophys. Res. Lett., 6, 301-304, 1979.

Kelly, M. C.: The Earth's ionospher, Academic, San Diego, Calif., 1989.

Kikuchi, T., Luhr, H., Kitamura, T., Saka, O., and Schlegel, K.: Direct penetration of the polar electric field to the equator during a DP2 event as detected by the auroral and equatorial magnetometer chains and the EISCAT radar, J. Geophys. Res., 101(A8), 17161-17173, 1996.

Kikuchi, T., Hashimoto, K. K., and Nozaki, K.: Penetration of magnetospheric electric fields to the equator during a geomagnetic storm, J. Geophys. Res., 113, A06214, doi:10.1029/2007JA012628, 2008.

Kikuchi, T. and Araki, T.: Horizontal transmission of the polar electric field to the equator, J. Atmos. Sol. Terr. Phys., 41, 927-936, 1979.

Kil, H., Oh, S.-J., Paxton, L. J., Zhang, Y., Su, S.-Y., and Min, K.W.: Spike-like change of the vertical $\boldsymbol{E} \times \boldsymbol{B}$ drift in the equatorial region during very large geomagnetic storms, Geophys. Res. Lett., 34, L09103, doi:10.1029/2007GL029277, 2007.

Kirchengast, G., Hocke, K., and Schlegel, K.: The gravity wave TID relationship: Insight via theoretical model - EISCAT data comparison, J. Atmos. Terr. Phys., 58, 233-243, 1996.

Kudeki, E., Bhattacharyya, S., and Woodman, R. F.: A new approach in incoherent scatter F-region $\boldsymbol{E} \times \boldsymbol{B}$ drift measurements at Jicamarca, J. Geophys. Res., 104, 28145-28162, 1999.

Kumar S., Chandra, H., and Sharma, S.: Geomagnetic storms and their ionospheric effects observed at the equatorial anomaly crest in the Indian region, J. Atmosph. Sol. Terr. Phys., 67, 581-594, 2005.

Lin, C. H., Richmond, A. D., Liu, J. Y., Yeh, H. C., Paxton, L. J., Lu, G., Tsai, H. F., and Su, S.-Y.: Large scale variations of the low-latitude ionosphere during the octobar-november 2003 superrtorm: observational results, J. Geophys. Res., 110, A09S28, doi:10.1029/2004JA010900, 2005.

Liu, J. Y., Tsai, H. F., Tseng, C. L., Tasil.-C., Liou, K., and Chao, K.: The Effect Of Geomagnetic Storm Ionospheric Total Electron Content At The Equatorial Anomaly Region, Adv. Space. Res., 24, 1491-1494, 1999.

Ma, G. and Maruyama, T.: Derivation of TEC and estimation of instrumental biases from GEONET in Japan, Ann. Geophys., 21, 2083-2093, 2003, http://www.ann-geophys.net/21/2083/2003/.

Mannucci, A. J., Tsurutani, B. T., Komjathy, A., Saito, A., Gonzalez, W. D., Guarnierir, F. L., Kozyara, J. U., and Skoug, R.: Dayside Global Ionospheric Responce To The Major Interplanetry Events Of October 29-30, 2003 "Halloween Storms", Geophys. Res. Lett., 32, L12S02, doi:10.1029/2004GL021467, 2005.

Maruyama, N., Richmond, A. D., Fuller-Rowell, T. J., Codrescu, M. V., Sazykin, S., Toffoletto, F. R., Spiro, R. W., and Millward, G. H.: Interaction between direct penetration and disturbance dynamo electric fields in the storm-time equatorial ionosphere, Geophys. Res. Lett., 32, L17105, doi:10.1029/2005GL023763, 2005.
Maruyamaa, N., Sazykin, S., Spiro, R. W., Anderson, D., Anghel, A., Wolf, R. A., Toffoletto, F. R., Fuller-Rowell, T. J., Codrescu, M. V., Richmond, A. D., and Millward, G. H.: Modeling storm-time electrodynamics of the low-latitude ionospherethermosphere system: Can long lasting disturbance electric fields be accounted for?, J. Atmos. Sol. Terr. Phys., 69, 1182-1199, 2007.

Maruyama, T., Ma, G. Y., and Nakamura, M.: Signature of TEC storm on 6 November 2001 derived from dense GPS receiver network and ionospheric chain over Japan, J. Geophys. Res., 109 1-11, A10302, doi:10.1029/2004JA010451, 2004.

Millward, G. H., Moffett, R. J., Quegan, S., and Fuller-Rowell, T. J.: Effects of an atmospheric gravity wave on the midlatitude ionospheric F Layer, J. Geophys. Res., 98, 19173-19179, 1993.

Nicolls, M. J., Kelley, M. C., Coster, A. J., González, S. A., and Makela, J. J.: Imaging the structure of a large-scale TID using ISR and TEC data, Geophys. Res. Lett., 31, L09812, doi:10.1029/2004GL019797, 2004.

Nishida, A.: Coherence of geomagnetic DP2 magnetic fluctuations with interplanetary magnetic variations, J. Geophys. Res. 73(17), 5549-5559, 1968.

Peymirat, C., Richmond, A. D., and Kobea, A. T.: Electrodynamic coupling of high and low latitudes: Simulations of shielding/overshielding effects, J. Geophys. Res., 105, 22991-23003, 2000.

Prolss, G. W.: On explaining the local time variation of ionospheric storm effects, Ann. Geophys., 11, 1-9, 1993, http://www.ann-geophys.net/11/1/1993/.

Prolss, G. W. and Ocko, M.: Propagation of upper atmospheric storm effects towards lower latitudes, Adv. Space Res., 26(1), 131-135, 2000.

Rastogi, R. G. and Klobuchar, J. A.: Ionospheric electron content within the equatorial anomaly belt, J. Geophys. Res., 95, 1904519052,1990.

Rastogi, R. G.: Disturbance daily variation of electrojet current at Indian longitude sector, J. Atmos. Sol. Terr. Phys., 62, 695-700, 2000.

Richmond, A. D.: Gravity wave generation, propagation, and dissipation in the thermosphere, J. Geophys. Res., 83, 4131-4145, 1978.

Sastri, J. H.: Equatorial electric field of ionospheric disturbance dynamo origin, Ann. Geophys., 6(67), 635-642, 1988.

Sastri, J. H., Ramesh, K. B., and Rangnath Rao, H. N.: Transient composite electric field disturbances near dip equator associated with auroral substorms, Geophys. Res. Lett., 19, 1451-1454, 1992a.

Sastri, J. H., Ramesh, K. B., and Karunakaran, D.: On the nature of substorm-related transient electric field disturbances in the equatorial ionosphere, Planet. Space Sci., 40, 95-103, 1992b.

Sastri, J. H., Jyoti, N., Somayajulu, V. V., Chandra, H., and Devasia, C. V.: Ionospheric storm of early November 1993 in the Indian equatorial region, J. Geophys. Res., 105, 18443-18455, 2000.

Scherliess, E. and Fejer, B. G.: Radar and satellite global equatorial F-region vertical drift model, J. Geophys. Res., 104, 6829-6842, 1999.

Somayajulu, V. V., Reddy, C. A., and Viswanathan, K. S.: Penetration of magnetospheric convective electric field to the equatorial ionosphere during the substorm of March 22, 1979, Geophys. Res. Lett., 14(8), 876-879, 1987.

Tsugawa, T., Saito, A., and Otsuka, Y.: A statistical study 
of largescale traveling ionospheric disturbances using the GPS network in Japan, J. Geophys. Res., 109(9), A06302, doi:10.1029/2003JA010302, 2004.

Tsurutani, B., Mannucci, A., Iijima, B., Abdu, M. A., Sobral, J., Humberto, A., Gonzalez, W., Guarnieri, F., Tsuda, T., Saito, A., Yumoto, K., et al.: Global Dayside Ionospheric Uplift And Enhancement Associted With Interplanetary Electric Field, J. Geophys. Res., 109, A08302, doi:10.1029/2003JA010342, 2004.
Woodman, R. F.: Vertical drift velocities and east-west electric fieldsat the magnetice quator, J. Geophys. Res., 75, 6249-6259, 1970.

Zhao, B., Wan, W., and Liu, L.: Responses of equatorial anomaly to the October-November 2003 superstorms, Ann. Geophys., 23, 693-706, 2005, http://www.ann-geophys.net/23/693/2005/. 